\title{
Food viscosity as determinant for adaptive growth responses in rat intestine: long-term feeding of different hydroxyethyl celluloses
}

\author{
Bernd Elsenhans $^{1 *}$ and Wolfgang F. Caspary ${ }^{2}$ \\ ${ }^{1}$ Walther Straub-Institut für Pharmakologie und Toxikologie der Ludwig-Maximilians-Universität München, \\ Nussbaumstrasse 26, D-80336 München, Germany \\ ${ }^{2}$ Abteilung Gastroenterologie, Zentrum Innere Medizin, Johann Wolfgang Goethe-Universität, Theodor-Stern-Kai 7, \\ D-60596 Frankfurt am Main, Germany
}

(Received 1 April 1999 - Revised 11 October 1999 - Accepted 8 December 1999)

\begin{abstract}
Carbohydrate gelling agents can be regarded as being representative for the soluble and viscous fractions of dietary fibre. Their dietary concentration affects the consistency of the ingested food as well as the dilution of nutrients and energy. By feeding hydroxyethyl cellulose (HEC) differing in molecular mass, and thus in its viscosity properties, only the consistency of the diet was modified. Three HEC (of low (LV), medium (MV) and high viscosity (HV)) were employed in a 6 -week feeding study with female rats to evaluate the effect of the viscosity on adaptive responses of intestinal growth variables. Each of the HEC was added in three increasing concentrations (8, 16 , and $32 \%, \mathrm{w} / \mathrm{w}$ ) to a fibre-free control diet to yield nine test groups besides a fibre-free and an additional, fibre-rich, cereal-based control group. Except for the highest concentration of the high viscosity product ( $32 \%$ HV-HEC), the dilution of the energy density of the diet was almost completely compensated by an increased food intake. With the same exception, energy utilisation was not impaired and, therefore, body-weight gains in the test groups were not significantly different from that in the control. Most other changes, e.g. increases in small intestinal length, mucosal DNA content, caecal and colonic weight, not only depended on the dietary concentration but also on the viscosity of HEC in a manner that either increasing the viscosity at a given dietary concentration or increasing the dietary concentration at a given viscosity led to the same results. These findings clearly prove the important role of the viscosity of the lumen content, as a mere physico-chemical factor, in determining adaptative growth responses in the intestinal tract of rats.
\end{abstract}

Intestinal adaptation: Dietary fibre: Food viscosity: Hydroxyethyl cellulose

Dietary fibre influences digestion, and absorption of nutrients directly and by means of adaptive changes of the gastrointestinal tract (for review see Spiller, 1994). Since dietary fibre represents a complex and inconstant mixture of structural and reserve food carbohydrates (Southgate, 1978), it is often difficult to attribute particular effects of dietary fibre to specific components.

Previously several carbohydrate gelling agents were investigated for their effect on adaptive responses of the gastrointestinal tract of rats after long-term administration with the diet (Elsenhans et al. 1981). The results demonstrated that chemically different polysaccharides produce similar changes in the small intestine. Caecal and colonic changes were mainly determined by the microbiological degradability of the polysaccharides.

Polysaccharides belonging to the class of carbohydrate gelling agents may be at least in part representative for the soluble portion of dietary fibre. As such they may serve as model substances in nutritional studies. Furthermore, some of these polysaccharides, e.g. guaran and pectin, were proposed as therapeutic agents in the treatment of adipositas and diabetes. One of the most outstanding features of these polysaccharides is their ability to increase the viscosity of aqueous media. This property is likely to play a role in the development of adaptive changes in the intestine. However, adding carbohydrate gelling agents in increasing concentrations to a fibre-free diet not only changes the consistency of the lumen content of the gastrointestinal tract, but also leads to an increased dilution of nutrients and dietary energy.

The viscosity-enhancing properties of soluble polysaccharides, with repeating carbohydrate units of the same chemical structure, correlate with their relative molecular mass. The longer molecules form networks within a solution easier and hence lead to higher viscosities than shorter ones. Feeding such polysaccharides of different chain length, i.e. homologous polysaccharides, should enable study of the 
effect of the viscosity independently of the effect of dilution. The same amounts of those polysaccharides but differing in molecular mass should alter mainly the consistency of the food, but should leave the dilution of nutrients and energy essentially unchanged. The present study attempts to elucidate the effect of the viscosity of carbohydrate gelling agents as such by feeding various hydroxyethyl celluloses (HEC) to rats.

\section{Materials and methods}

\section{Animals}

Female Wistar rats (Zentralinstitut für Versuchstiere, Hannover, Germany), with a body weight of 85-105 $\mathrm{g}$ on arrival, were used in the present investigation. Animal experiments were performed according to the guidelines required by the German animal protection law. The rats were housed in wire-bottomed stainless-steel cages (four rats per cage) in a temperature-controlled room $\left(22^{\circ} \mathrm{C}\right)$ maintained on a $12 \mathrm{~h}$ light-dark schedule and allowed $7 \mathrm{~d}$ to acclimatize before the commencement of the feeding experiment. Before and during the experiment, the animals were fed pelleted diets available ad libitum and had free access to tap water. According to the number of the different diets, animals were divided into eleven groups of eight animals each.

\section{Diets}

In the acclimatization period all rats and then in the feeding experiment the control group (designated as $0 \%$ group) received the basal fibre-free diet (C 1015, Altromin GmbH, Lage, Germany) composed of the following ingredients $(\%)$ : casein 22 , starch 57 , sucrose 10 , soyabean oil (refined) 3 , minerals and trace elements 6 , vitamin mixture 2 , a diet previously described in more detail (Elsenhans \& Caspary, 1989). For each of the three HEC tested (high viscosity (HV), medium viscosity (MV) and low viscosity (LV); Table 1) three groups were set up, an 8,16 , and $32 \%$ group according to the amount $(\mathrm{w} / \mathrm{w})$ of polysaccharide added to the control diet. For further comparison an additional group (STD group) was run parallel to the others; these animals received a cerealbased standard rat diet (1320, Altromin GmbH, Lage, Germany). Based on the data provided by the manufacturer, a comparison of the two diets employed is given in Table 2 .

\section{Experimental procedure}

Body-weight gains were recorded weekly; food intake measurements were made in 3 to $4 \mathrm{~d}$ intervals as the food
Table 2. Analysis of the raw nutrients of the diets (\%) employed ${ }^{*}$

\begin{tabular}{lcc}
\hline Diet ... & Fibre-free & Fibre-rich \\
\cline { 2 - 3 } Abbreviation ... & 0\% (C 1015)† & STD (C 1320)† \\
\hline Raw protein & 17.5 & 19.0 \\
Raw fat & 3.0 & 4.0 \\
Raw fibre & traces & 6.0 \\
Ash & 7.0 & 7.0 \\
Water & 12.0 & 13.5 \\
Nitrogen-free extracts§ & & 50.5 \\
Available energy (kJ/kg) & 13810 & 12980 \\
\hline
\end{tabular}

* Data supplied by the manufacturer (Altromin, Lage, Germany).

†Designated by the manufacturer.

$\ddagger$ Raw fibre content is based on a residue analysis which is only a crude measure for the total dietary fibre content.

§ Mainly carbohydrates; no data are given for the diet C 1015 which was produced using $57 \%$ starch and $10 \%$ sucrose (see Diets section).

intake of the animals of one cage. At the end of the feeding period of 6 weeks, non-fasted animals were decapitated after being stunned by a blow on the head and bled. The small intestine, the caecum and the colon were removed after stripping off the mesentery. Organs were rinsed in ice-cold physiological saline, slit open, and the contents removed. Thereafter, the small intestine was divided into a proximal and distal half, the lengths of which were determined by holding the small intestinal segment in a hanging position. After rinsing again in saline, the cleaned organs were blotted on filter paper and weighed. The small intestinal mucosa was scraped off using a microscope glass slide, weighed, immediately frozen in an acetone-dry ice mixture and stored at $-20^{\circ} \mathrm{C}$ until analysed. After thawing, mucosal homogenates $(2 \%, \mathrm{w} / \mathrm{v})$ were prepared in a Waring-type blendor at full speed for $30 \mathrm{~s}$. Protein was measured according to the method of Lowry et al. (1951) and DNA by the method of Burton (1956) modified according to Croft \& Lubran (1965).

\section{Statistical treatment of results}

The data were treated in two ways (Sachs, 1984). Firstly, one-way ANOVA followed by the least-significant-difference (LSD) test was performed to determine the significance of the differences between the various dietary groups and to test which of them belong to homogeneous groups. Secondly, two-factor ANOVA was employed for data from the HECfed groups in order to determine whether the viscosity, the dietary concentration of the polysaccharide or both factors had significantly influenced the changes in the variables measured. The level of significance was set to $P<0 \cdot 05$.

Table 1. Properties of the hydroxyethyl celluloses (HEC) used in the present diets

\begin{tabular}{lcccc}
\hline Designation* & Abbreviation† & $\begin{array}{c}\text { Degree of } \\
\text { polymerisation }\end{array}$ & $\begin{array}{c}\text { Relative molecular } \\
\text { mass }\end{array}$ & $\begin{array}{c}\text { Viscosity } \\
\left(2 \% \text { in } \mathrm{H}_{2} \mathrm{O} ; \mathrm{cPa} \cdot \mathrm{s}\right)\end{array}$ \\
\hline HEC 20 & LV & 170 & 38000 & 0.02 \\
HEC 300 & MV & 410 & 90000 & 0.3 \\
HEC 4000 & HV & 740 & 185000 & 4.0 \\
\hline
\end{tabular}

${ }^{*}$ Designated by the commercial supplier (SERVA, Heidelberg, Germany). Degree of substitution $=2$ (i.e. two hydroxyethyl groups per glucose moiety).

†Used in the present study. 


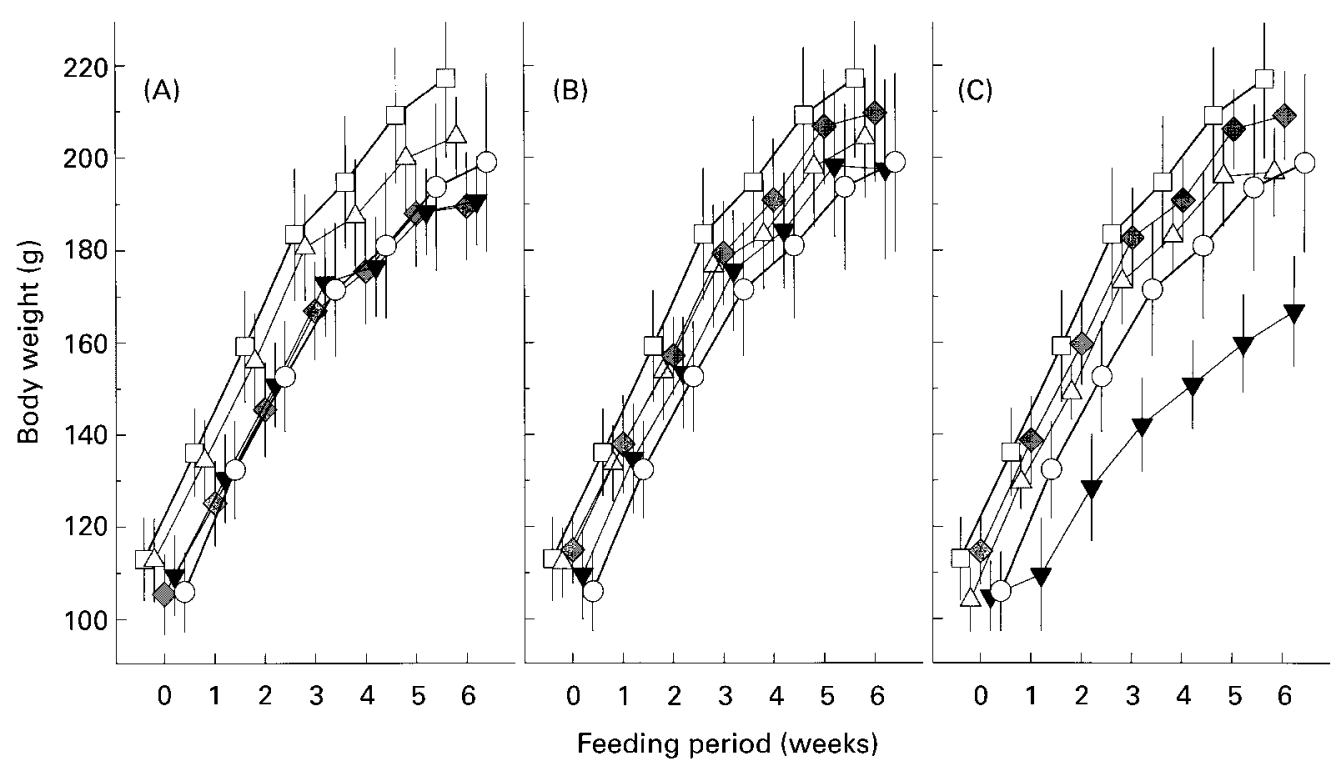

Fig. 1. Growth curves of rats; effects of increasing additions of (A) low-viscosity, (B) medium-viscosity and (C) high-viscosity hydroxyethyl cellulose to a basal fibre-free diet $(0 \%)$; STD, standard chow-fed group. $-\square-, 0 \% ;-\triangle-, 8 \% ;---, 16 \%,-\nabla-, 32 \%$; $-\bigcirc-$, STD. Values are means for eight rats per group with standard deviations represented by vertical bars. The growth curves of the fibre-free control and the standard chow-fed group are shown in each panel for better comparison with the individual growth curves of the hydroxyethyl cellulose-fed groups. For details of diets see Tables 1 and 2, and of procedures p. 40.

\section{Results}

\section{Animal growth and energy intake}

The growth of the animals of the various groups did not differ significantly with one exception (Fig. 1); on feeding a diet with a $32 \%$ addition of the high viscosity HEC, growth was significantly reduced. All the other growth curves were found in between the one obtained for the fibre-free control and the other obtained for the STD group. For a period of fairly linear growth (the first 3 weeks for most of the groups) the data on the daily body-weight gain show these differences more quantitatively (Table 3 ).

There was a slight reduction in the daily food intake of the $8 \%$-HEC diets when compared with the intake of the fibrefree control diet. This reduction was equally seen for all three HEC, but was not statistically significant, and is likely to be the result of a slight overestimation of the food intake of the $0 \%$ group. Losses due to crumbling of the food pellets were estimated to be in the range of $1-8 \%$; the pellets of the fibre-free diet $(0 \%)$ were particularly crumbly, so losses of the other diets were much smaller $(<2 \%)$ because of their more solid pellets. By raising the HEC concentration in all three HEC diets (LV, MV, and HV) an increase in the daily food intake was observed as compared to the intake in the fibre-free control group. The increase, however, was not observed for the rats receiving the diet with $32 \% \mathrm{HEC}$ of high viscosity (data not shown). With this particular exception, the pattern of food intake resulted in a rather uniform energy intake of the HEC-fed animals as calculated from the food intake and the energy content of the corresponding diet (Table 3). For these calculations HEC was assumed not to contribute to the amount of available energy.

From these results, energy utilization (mg body weight gain $/ \mathrm{kJ}$ ) was calculated to be on an average in the range $18.5-20.4 \mathrm{mg} / \mathrm{kJ}$ in the HEC-fed groups except for that receiving the $32 \%$ diet with the $\mathrm{HV}$ cellulose derivative $(14.0 \mathrm{mg} / \mathrm{kJ}$, significantly lower than in the other groups, $P<0.05)$.

Table 3. Effect of viscosity and concentration of dietary hydroxyethyl celluloses (HEC) on the daily weight gain and daily energy intake of rats (Mean values and standard deviations for eight rats per group)

\begin{tabular}{|c|c|c|c|c|c|c|c|c|c|c|c|c|c|c|c|c|c|c|c|}
\hline \multirow{3}{*}{$\begin{array}{l}\text { Viscosity of HEC ... } \\
\text { Dietary addition } \\
\text { of HEC (\%) }\end{array}$} & \multicolumn{10}{|c|}{ Daly weight gain (g/d) } & \multicolumn{9}{|c|}{ Daily energy intake $(\mathrm{kJ} / \mathrm{d}) \dagger$} \\
\hline & \multicolumn{2}{|c|}{$0 \%$} & \multicolumn{2}{|c|}{ LV } & \multicolumn{2}{|c|}{ MV } & \multicolumn{2}{|c|}{ HV } & \multicolumn{2}{|c|}{ STD } & \multicolumn{2}{|c|}{$0 \%$} & \multicolumn{2}{|c|}{ LV } & \multicolumn{2}{|c|}{ MV } & \multicolumn{2}{|c|}{ HV } & STD \\
\hline & Mean & SD & Mean & SD & Mean & SD & Mean & SD & Mean & SD & Mean & SD & Mean & SD & Mean & SD & Mean & SD & Mean SD \\
\hline- & $3.1^{a}$ & 0.1 & & & & & & & $2 \cdot 9^{a}$ & 0.2 & $177^{\mathrm{a}}$ & 14 & & & & & & & $219^{d} 20$ \\
\hline 8 & & & $\begin{array}{l}3.0^{\mathrm{a}} \\
2.7^{\mathrm{a}}\end{array}$ & $\begin{array}{l}0.1 \\
0.1\end{array}$ & $2 \cdot 8^{a}$ & $\begin{array}{l}0.2 \\
0.4\end{array}$ & $\begin{array}{l}3.0^{\mathrm{a}} \\
3.0^{\mathrm{a}}\end{array}$ & $\begin{array}{l}0.3 \\
0.1\end{array}$ & & & & & $\begin{array}{l}155^{\mathrm{ab}} \\
146^{\mathrm{b}}\end{array}$ & $\begin{array}{r}7 \\
12\end{array}$ & $\begin{array}{l}150^{\mathrm{b}} \\
152^{\mathrm{b}}\end{array}$ & $\begin{array}{c}4 \\
12\end{array}$ & $\begin{array}{l}154^{\mathrm{b}} \\
155^{\mathrm{ab}}\end{array}$ & $\begin{array}{l}16 \\
28\end{array}$ & \\
\hline $\begin{array}{l}16 \\
32\end{array}$ & & & $\begin{array}{l}2 \cdot 7^{\mathrm{a}} \\
2 \cdot 8^{\mathrm{a}}\end{array}$ & $\begin{array}{l}0.1 \\
0.1\end{array}$ & $\begin{array}{l}2 \cdot 8^{\mathrm{a}} \\
2 \cdot 9^{\mathrm{a}}\end{array}$ & $\begin{array}{l}0.4 \\
0.4\end{array}$ & $\begin{array}{l}3.0^{\mathrm{a}} \\
1.7^{\mathrm{b}}\end{array}$ & $\begin{array}{l}0.1 \\
0.9\end{array}$ & & & & & $\begin{array}{l}146^{\mathrm{D}} \\
144^{\mathrm{b}}\end{array}$ & $\begin{array}{l}12 \\
12\end{array}$ & $\begin{array}{l}152^{D} \\
147^{b}\end{array}$ & $\begin{array}{l}12 \\
31\end{array}$ & $\begin{array}{l}155^{\mathrm{ad}} \\
121^{\mathrm{c}}\end{array}$ & $\begin{array}{l}28 \\
32\end{array}$ & \\
\hline
\end{tabular}

$0 \%$, Fibre-free control; LV, low viscosity; MV, medium viscosity; HV, high viscosity; STD, standard group.

$\mathrm{a}, \mathrm{b}, \mathrm{c}, \mathrm{d}$ Mean values with unlike superscript letters were significantly different (one-way ANOVA and least-significant-difference test): $P<0.05$.

$\dagger$ Based on the food consumption of each group during the first 3 weeks of the feeding experiment. 


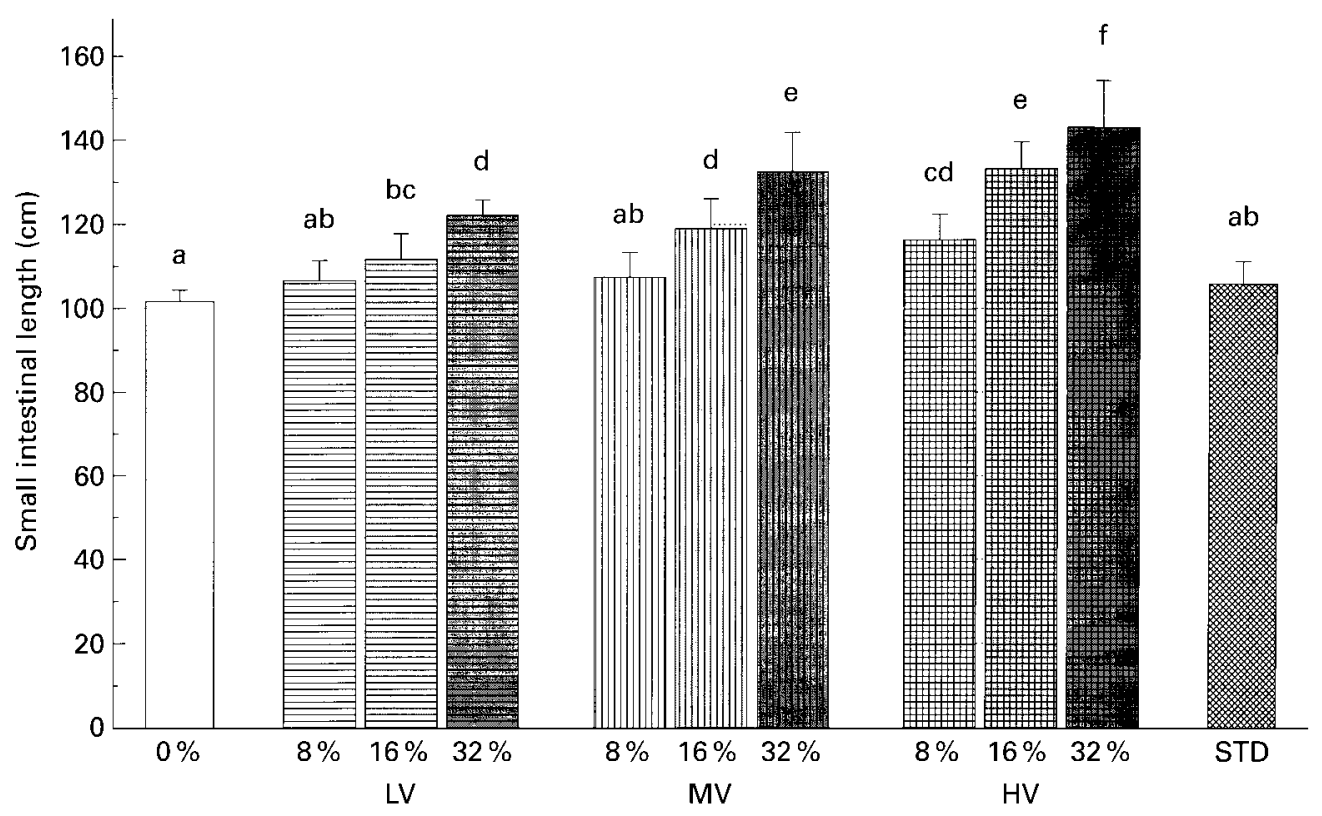

Fig. 2. Effect of feeding different viscous hydroxyethyl celluloses at three different dietary concentrations (8, 16 and $32 \%)$ on the length of the small intestine. Values are means for eight rats per group with standard deviations represented by vertical bars. $0 \%$, Fibre-free control; STD, standard chow-fed group; LV, low viscosity; MV, medium viscosity; HV, high viscosity. ${ }_{a, b, c, d, e, f}$ Values with unlike superscript letters were significantly different (one-way ANOVA and least-significant-difference test): $P<0.05$. For details of diets see Tables 1 and 2, and of procedures $\mathrm{p}$. 40.

\section{Small intestine}

Feeding increasing additions of either one of three different HEC a continuous and significant increase was observed for the small intestinal length (Fig. 2). Most remarkably, an increasing viscosity of the cellulose derivative fed at either one of the three dietary concentrations led to a rather similar elongation of the small intestine. Thus, the dietary concentration and the viscosity of the HEC added to the diet were equally significant factors in determining the small intestinal length.

The different diets caused a rather large response on the small intestinal wet weight (Table 4). The increases were larger than those observed for the length. Compared with the small intestinal weight of the $0 \%$ group, that of the groups fed HEC at a dietary concentration of $32 \%$ increased by approximately $30 \%, 70 \%$, and $100 \%$ feeding the LV, MV and HV derivative respectively. The increases in the weight showed the same dependency on either the dietary concentration or the viscosity properties of the cellulose derivative added to the diets as were shown for the small intestinal length.

In quite a similar manner mucosal wet weight increased when increasing additions of the three HEC were fed or when at one dietary concentration viscosity increased (data not shown). When related to the small intestine length

Table 4. Influence of the various dietary hydroxyethyl celluloses (HEC) on the wet weight of the small intestine (g)* (Mean values and standard deviations for eight rats per group)

\begin{tabular}{|c|c|c|c|c|c|c|c|c|c|c|c|}
\hline \multirow[b]{3}{*}{ Dietary addition of HEC (\%) } & \multicolumn{10}{|c|}{ Viscosity of HEC } & \multirow{3}{*}{$\begin{array}{l}\text { Statistical significance } \\
\text { (two-way ANOVA): } P<\end{array}$} \\
\hline & \multicolumn{2}{|c|}{$0 \%$} & \multicolumn{2}{|c|}{ LV } & \multicolumn{2}{|c|}{ MV } & \multicolumn{2}{|c|}{ HV } & \multicolumn{2}{|c|}{ STD } & \\
\hline & Mean & SD & Mean & $\mathrm{SD}$ & Mean & SD & Mean & SD & Mean & SD & \\
\hline- & 5.71 & $0.34^{a}$ & & & & & & & $6 \cdot 50^{\mathrm{bc}}$ & 0.70 & \\
\hline 8 & & & $6 \cdot 04^{\mathrm{ab}}$ & 0.42 & $5 \cdot 72^{a}$ & 0.82 & $6 \cdot 96^{\mathrm{cd}}$ & 0.83 & & & Main effects \\
\hline 16 & & & $6 \cdot 60^{\mathrm{bc}}$ & 0.97 & $7 \cdot 48^{d}$ & 0.65 & $9 \cdot 34^{e}$ & 1.08 & & & $\begin{array}{l}\text { viscosity } 0.05 \\
\text { concentration } 0.05 \\
\text { interactions } 0.05\end{array}$ \\
\hline 32 & & & $7 \cdot 48^{d}$ & 0.64 & $9.86^{\mathrm{e}}$ & $1 \cdot 18$ & $11.62^{f}$ & 1.05 & & & \\
\hline
\end{tabular}

HEC, hydroxyethyl cellulose; 0\%, fibre-free control; LV, low viscosity; MV, medium viscosity; HV, high viscosity; STD, standard group.

$a, b, c, d, e, f$ Mean values with unlike superscript letters were significantly different (one-way ANOVA and least-significant-difference test): $P<0.05$.

${ }^{*}$ For details of hydroxyethyl celluloses and diets see Tables 1 and 2, and for procedures see p. 40. 
Table 5. Effect of viscosity and concentration of dietary hydroxyethyl cellulose on the mucosal wet weight per unit length $(\mathrm{mg} / \mathrm{cm})$ in the proximal and distal small intestine*

(Mean values and standard deviations for eight rats per group)

\begin{tabular}{|c|c|c|c|c|c|c|c|c|c|c|c|}
\hline \multirow[b]{3}{*}{ Dietary addition of HEC (\%) } & \multicolumn{10}{|c|}{ Viscosity of HEC } & \multirow{3}{*}{$\begin{array}{l}\text { Statistical significance } \\
\text { (two-way ANOVA): } P<\end{array}$} \\
\hline & \multicolumn{2}{|c|}{$0 \%$} & \multicolumn{2}{|c|}{ LV } & \multicolumn{2}{|c|}{ MV } & \multicolumn{2}{|c|}{ HV } & \multicolumn{2}{|c|}{ STD } & \\
\hline & Mean & $\mathrm{SD}$ & Mean & SD & Mean & SD & Mean & SD & Mean & SD & \\
\hline $\begin{array}{l}\text { Proximal small intestine } \\
\quad \overline{8}\end{array}$ & $35 \cdot 7^{\mathrm{abc}}$ & 2.5 & $34 \cdot 6^{\mathrm{ab}}$ & $2 \cdot 1$ & $33 \cdot 2^{a}$ & 3.9 & $38.9^{\mathrm{bcd}}$ & 3.6 & $40.9^{\text {de }}$ & $4 \cdot 8$ & \\
\hline 16 & & & $35 \cdot 5^{\mathrm{abc}}$ & 4.4 & $39.5^{\text {cde }}$ & 3.5 & $44.0^{e}$ & $5 \cdot 7$ & & & $\begin{array}{l}\text { Main effects } \\
\text { viscosity } 0.05 \\
\text { concentration } 0.05 \\
\text { interactions NS }\end{array}$ \\
\hline $\begin{array}{l}\text { Distal small intestine } \\
\quad- \\
8\end{array}$ & $23 \cdot 4^{\mathrm{a}}$ & 3.8 & $24 \cdot 0^{a}$ & 3.8 & $24 \cdot 8^{\mathrm{ab}}$ & $5 \cdot 7$ & $25 \cdot 2^{\mathrm{ab}}$ & 3.4 & $32 \cdot 3^{\mathrm{cd}}$ & 3.5 & \\
\hline 16 & & & $24 \cdot 3^{a b}$ & 2.5 & $30 \cdot 7^{\mathrm{cd}}$ & 3.8 & $31 \cdot 0^{c d}$ & 3.9 & & & $\begin{array}{l}\text { Main effects } \\
\text { viscosity } 0.05 \\
\text { concentration } 0.05 \\
\text { interactions } 0.05\end{array}$ \\
\hline
\end{tabular}

HEC, hydroxyethyl cellulose; $0 \%$, fibre-free control; LV, low viscosity; MV, medium viscosity; HV, high viscosity; STD, standard group.

a,b,c,d,e,f Mean values with unlike superscript letters were significantly different (one-way ANOVA and least-significant-difference test): $P<0.05$.

${ }^{*}$ For details of hydroxyethyl celluloses and diets see Tables 1 and 2, and for procedures see p. 40.

(Table 5), however, the increases were slightly lesser and in the range of 0 to $50 \%$. Although lesser in the distal half, mucosal wet weight per unit of length showed a similar pattern of dependency on either dietary concentration or viscosity of HEC in both parts of the small intestine.

Mucosal protein content increased together with the small intestine mucosal weight. Therefore, protein content related to the intestine length did not change drastically or systematically by feeding the various diets. In the proximal portion of the small intestine of all groups, the protein content per length was between 4.74 (SD 0.49) (LV-HEC, 16\%) and 5.55 $(\mathrm{SD} 0.67) \mathrm{mg} / \mathrm{cm}(\mathrm{MV}-\mathrm{HEC}, 16 \%)$ and showed only few significant differences $(P<0.05)$ among the HEC-fed groups as well as with respect to the $0 \%$ group $(5.08(\mathrm{SD} 0 \cdot 32) \mathrm{mg} /$ $\mathrm{cm})$ or the STD group $(5.47(\mathrm{SD} 0.85) \mathrm{mg} / \mathrm{cm})$. Although lower in general, a similar pattern of the results was obtained for the distal half. Mucosal protein content per unit length was between 2.67 (SD 0.38) (MV-HEC, $8 \%$ ) and 3.40 (SD 0.33) mg/cm (HV-HEC, $32 \%$ ). Within all HEC groups the protein content in the distal mucosa increased slightly as the HEC levels in the food increased; the increase in viscosity was without effect. Compared with the protein content in the distal mucosa of the $0 \%$ control group (3.08 $(\mathrm{SD} 0.27) \mathrm{mg} / \mathrm{cm})$, the changes in this variable in the HEC groups were not statistically significant, however. Mucosal protein content was highest in the STD group (4.04 (SD $0.57) \mathrm{mg} / \mathrm{cm}$ ). In general, mucosal protein level was slightly less affected by the differences in the food composition as compared to the mucosal wet weight. On average, a $10 \%$ increase in the mucosal wet weight led to an $8 \%$ increase in the mucosal protein level.

The changes in the mucosal DNA content per unit length observed after feeding the various HEC diets were similar to those observed for the mucosal protein content (Table 6). However, differences between the various HEC groups turned out to be more pronounced so that the influence of the dietary HEC concentration as well as of the viscosity increase was found to be of statistical significance $(P<0.05)$.

With these findings, the effect of feeding the HEC diets on the protein: DNA ratio are explained. Owing to the less changed protein and the more increased DNA levels in the mucosa, the ratio decreases in the HEC-fed groups (Table 7). In the distal half of the small intestine this pattern seems more distinct than in the proximal half. While the effect of an increase in the dietary HEC concentration on this ratio showed only slight changes, the increase in viscosity significantly decreased the protein : DNA ratio in the proximal as well as in the distal small intestine.

\section{Caecum and colon}

Changes in caecal and colonic weight were determined to roughly characterize the effects of the HEC additions on the distal parts of the intestinal tract (Fig. 3). The weight of the caecum and colon significantly increased either by increasing the dietary concentration or the viscosity of the HEC additions. Compared to the $0 \%$ group the maximum 
Table 6. Effect of viscosity and concentration of dietary hydroxyethyl cellulose on the DNA content per unit length $(\mu \mathrm{g} / \mathrm{cm})$ in the proximal and distal small intestine*

(Mean values and standard deviations for eight rats per group)

\begin{tabular}{|c|c|c|c|c|c|c|c|c|c|c|c|}
\hline \multirow[b]{3}{*}{ Dietary addition of HEC (\%) } & \multicolumn{10}{|c|}{ Viscosity of HEC } & \multirow{3}{*}{$\begin{array}{l}\text { Statistical significance } \\
\text { (two-way ANOVA): } P<\end{array}$} \\
\hline & \multicolumn{2}{|c|}{$0 \%$} & \multicolumn{2}{|c|}{ LV } & \multicolumn{2}{|c|}{ MV } & \multicolumn{2}{|c|}{ HV } & \multicolumn{2}{|c|}{ STD } & \\
\hline & Mean & SD & Mean & SD & Mean & SD & Mean & SD & Mean & SD & \\
\hline Proximal small intestine: & & & & & & & & & & & \\
\hline$\overline{8}$ & $170^{\mathrm{ab}}$ & 14 & $170^{a}$ & 9 & $184^{\mathrm{abc}}$ & 33 & $207^{\text {cd }}$ & 50 & $186^{\mathrm{abc}}$ & 29 & \\
\hline 16 & & & $167^{\mathrm{a}}$ & 27 & $198^{\mathrm{bcd}}$ & 23 & $199^{c d}$ & 16 & & & $\begin{array}{l}\text { Main effects } \\
\text { viscosity } 0.05 \\
\text { concentration } 0.05 \\
\text { interactions NS }\end{array}$ \\
\hline 32 & & & $208^{c d}$ & 34 & $219^{d}$ & 26 & $216^{d}$ & 9 & & & \\
\hline $\begin{array}{l}\text { Distal small intestine: } \\
\frac{-}{8}\end{array}$ & $117^{a}$ & 17 & $133^{a b c}$ & 23 & $134^{\mathrm{abc}}$ & 23 & $156^{\text {cde }}$ & 31 & $194^{f}$ & 24 & \\
\hline 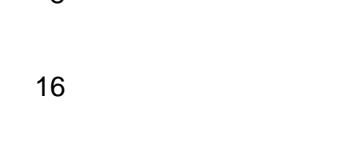 & & & $131^{\mathrm{ab}}$ & 12 & $178^{\mathrm{e}}$ & 25 & $170^{\mathrm{de}}$ & 30 & & & $\begin{array}{l}\text { Main effects } \\
\text { viscosity } 0.05 \\
\text { concentration } 0.05 \\
\text { interactions NS }\end{array}$ \\
\hline 32 & & & $148^{\mathrm{bcd}}$ & 25 & $171^{\mathrm{de}}$ & 25 & $167^{\text {de }}$ & 21 & & & \\
\hline
\end{tabular}

HEC, hydroxyethyl cellulose; 0\%, fibre-free control; LV, low viscosity; MV, medium viscosity; HV, high viscosity; STD, standard group.

$a, b, c, d, e, f$ Mean values with unlike superscript letters were significantly different (one-way ANOVA and least-significant-difference test): $P<0.05$.

${ }^{*}$ For details of hydroxyethyl celluloses and diets see Tables 1 and 2, and for procedures see p. 40.

increases in the organ weights were observed for the group receiving the $\mathrm{HV}-\mathrm{HEC}$ at its highest dietary concentration, the caecum and the colon weight in this group increased by factors of 2.5 and 4 respectively. The dose-dependence differed between the two organs, however. Whereas colonic weight appeared to level off with increasing dietary HEC additions at a given viscosity, the opposite was seen in the case of the caecal weight. Caecal weight increased in

Table 7. Influence of viscosity and concentration of dietary hydroxyethyl cellulose on the mucosal protein : DNA ratio in the proximal and distal small intestine*

(Mean values and standard deviations for eight rats per group)

\begin{tabular}{|c|c|c|c|c|c|c|c|c|c|c|c|}
\hline \multirow[b]{3}{*}{ Dietary addition of HEC (\%) } & \multicolumn{10}{|c|}{ Viscosity of HEC } & \multirow{3}{*}{$\begin{array}{l}\text { Statistical significance } \\
\text { (two-way ANOVA): } P<\end{array}$} \\
\hline & \multicolumn{2}{|c|}{$0 \%$} & \multicolumn{2}{|c|}{ LV } & \multicolumn{2}{|c|}{ MV } & \multicolumn{2}{|c|}{$\mathrm{HV}$} & \multicolumn{2}{|c|}{ STD } & \\
\hline & Mean & $\mathrm{SD}$ & Mean & $\mathrm{SD}$ & Mean & SD & Mean & $\mathrm{SD}$ & Mean & SD & \\
\hline \multicolumn{12}{|l|}{ Proximal small intestine: } \\
\hline - & $30 \cdot 0^{a}$ & 3.5 & & & & & & & $29 \cdot 5^{a b}$ & $3 \cdot 2$ & \multirow{4}{*}{$\begin{array}{l}\text { Main effects } \\
\text { viscosity } 0.05 \\
\text { concentration NS } \\
\text { interactions NS }\end{array}$} \\
\hline 8 & & & $29 \cdot 4^{\mathrm{ab}}$ & 4.6 & $26 \cdot 6^{\mathrm{abc}}$ & $2 \cdot 1$ & $25 \cdot 2^{c}$ & 2.5 & & & \\
\hline 16 & & & $29 \cdot 4^{a b}$ & $7 \cdot 8$ & $28 \cdot 1^{a b c}$ & $3 \cdot 3$ & $25 \cdot 1^{c}$ & $2 \cdot 0$ & & & \\
\hline 32 & & & $25 \cdot 0^{c}$ & 3.6 & $25 \cdot 4^{\mathrm{bc}}$ & $5 \cdot 4$ & $25 \cdot 3^{b c}$ & 1.9 & & & \\
\hline \multicolumn{12}{|l|}{ Distal small intestine } \\
\hline$\overline{8}$ & $26 \cdot 7^{a}$ & $2 \cdot 4$ & $22 \cdot 3^{b c}$ & $3 \cdot 4$ & $20 \cdot 3^{b c}$ & $4 \cdot 1$ & $18 \cdot 5^{c}$ & 2.1 & $20 \cdot 9^{b c}$ & $1 \cdot 3$ & \multirow{3}{*}{$\begin{array}{l}\text { Main effects } \\
\text { viscosity } 0.05 \\
\text { concentration NS } \\
\text { interactions NS }\end{array}$} \\
\hline 16 & & & $20 \cdot 5^{b c}$ & $2 \cdot 6$ & $18 \cdot 8^{c}$ & $1 \cdot 8$ & $18 \cdot 5^{c}$ & 1.5 & & & \\
\hline 32 & & & $23 \cdot 5^{a b}$ & 8.9 & $20 \cdot 3^{b c}$ & $4 \cdot 8$ & $20 \cdot 7^{b c}$ & 3.9 & & & \\
\hline
\end{tabular}

HEC, hydroxyethyl cellulose; $0 \%$, fibre-free control; LV, low viscosity; MV, medium viscosity; HV, high viscosity; STD, standard group.

${ }_{a, b, c}$ Mean values with unlike superscript letters were significantly different (one-way ANOVA and least-significant-difference test): $P<0.05$.

${ }^{*}$ For details of hydroxyethyl celluloses and diets see Tables 1 and 2 , and for procedures see p. 40. 


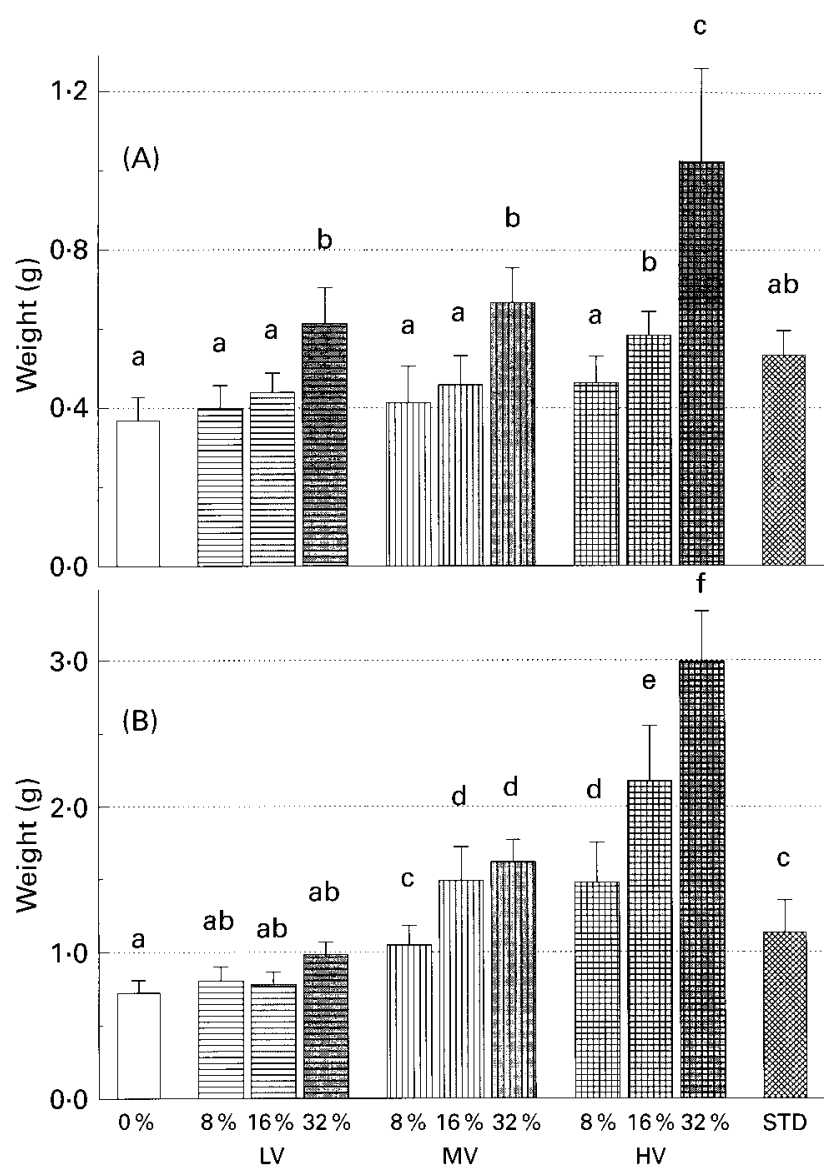

Fig. 3. Effect of feeding different viscous hydroxyethyl celluloses at three different dietary concentrations $(8,16$ and $32 \%)$ on the wet weight of $(A)$ the caecum or $(B)$ the colon. Values are means for eight rats per group with standard deviations represented by vertical bars. $0 \%$, Fibre-free control; STD, standard chow-fed group; LV, low viscosity; MV, medium viscosity; HV, high viscosity. a,b,c,d,e,fValues with unlike superscript letters were significantly different (one-way ANOVA and least-significant-difference test): $P<0.05$. For details of diets see Tables 1 and 2, and of procedures p. 40 .

particular after feeding diets with $32 \%$ HEC additions at any viscosity level.

\section{Discussion}

HEC belongs to a group of semisynthetically neutral cellulose ethers which are hardly degraded by micro-organisms. It can be presumed that HEC is not metabolized by rat intestinal bacteria, similarly to related cellulose derivatives, e.g. methylcellulose (Braun et al. 1974) and hydroxypropylcellulose (Gee et al. 1996). That HEC behaved like a nonfermentable polysaccharide when administered with the diet is seen by the response of the caecum and colon. In a previous study (Elsenhans et al. 1981) feeding microbiologically degradable polysaccharides to rats resulted in a higher weight gain of the caecum than of the colon, but feeding non-fermentable polysaccharides reversed that pattern, in fact, a pattern shown in the present study.

Since the administration of carbohydrate gelling agents with the food at high dietary concentrations $(>5 \%)$ is occasionally criticized and regarded to be inappropriate for rats (Struthers, 1986a), an annotation might be justified in this regard although a discussion of that matter has been published previously (Johnson, 1986; Struthers, $1986 b)$. Higher dietary concentrations have been tolerated quite well, e.g. $25 \%$ agar (Fischer, 1957) or $18 \%$ pectin (Brown et al. 1979), so that dietary concentrations of $32 \%$ are not unreasonably high, particularly not when attempting to describe an effect by its dose-dependence which, from a mechanistic and statistical point of view, is preferred to descriptions of effects at a single dose. That rats accept even higher dietary concentrations is also reflected by a previous study feeding diets with up to $40 \%$ additions of various carbohydrate gelling agents, in which body-weight gains did not indicate a major impairment of the animals, except perhaps for $40 \%$ additions of guaran (Elsenhans et al. 1981).

The addition of carbohydrate gelling agents to a fibre-free control diet generally leads to a lower growth rate of rats as the dietary concentration of the polysaccharide increases. This is particularly pronounced in case of microbiologically degraded polysaccharides which was shown in a previous study (Elsenhans et al. 1981). The reduction in body-weight gain was less distinct when less fermentable carbohydrate gelling agents were added to the diet. This resulted in an increased consumption of food so that the reduced energy concentration of the diet could be compensated for and growth was not impaired.

Feeding additions of the different HEC, the corresponding body-weight gains did not essentially differ from those obtained feeding the fibre-free control diet or the STD diet except for one group: feeding the HV-HEC at a concentration of $32 \%$ resulted in a reduced body-weight gain. Rats in this group could not compensate for the reduced energy density by increasing food intake which obviously marks a limit for such a compensation. It also demonstrates that this limit is not only a matter of the dietary concentration alone, but also a matter of the viscosity of the polysaccharide added since $32 \%$ additions of the LV-HEC were fully compensated for their lower energy density showing no reduced body-weight gain or energy utilization in this group.

The dependence on the food viscosity makes it plausible that this limit is much higher with indigestible fillers having only minor influence on the viscosity of the diet. In case of feeding kaolin to rats, this limit appears to be reached with dietary additions of approximately $66 \%$ (Dowling et al. 1967). In rats, such a limit was not obtained with other additives, e.g. dilutions of nutrients and energy by $40 \%$ cellulose (Mallett et al. 1983) or $50 \%$ polypropylene powder (Hiller \& Nebendahl, 1977) are well compensated for by corresponding increases in food intake. The behaviour to maintain energy supply by adaptation of the food intake is typical for rats and is maintained even after elimination of sensory influences (Epstein \& Teitelbaum, 1962).

Certainly, the exact nature of this limit is not clear yet. For microbiologically-degradable polysaccharides a contribution to the energy supply, at least partially, by utilization of fermentation products is supposed (Cummings, 1982), making compensatory food intake less distinct or negligible. In this respect, however, no quantitative data are available for rats (Schneeman, 1994) and, furthermore, this concept is 
not applicable for polysaccharides such as HEC that are not degraded by intestinal bacteria. Owing to the viscosity of the ingested polysaccharide, transport of unusually high amounts of undigested nutrients into distal parts of the intestine might contribute to a reduced food uptake (Atkinson et al. 1982), not only per se, but also through abdominal discomfort caused by gaseous fermentation products (Koopmans \& Maggio, 1978) or hormonal responses (Koopmans, 1990).

Many studies on the effect of dietary fibre upon growth of the caecum and colon emphasize the role of microbiological activities increased by fermentable dietary fibre as in contrast to non- or less-fermentable polysaccharides. In the present study fermentability of the HEC can be ignored so that changes in the caecal and colonic growth responses are mediated by their viscosity and dietary concentration, i.e. the consistency and mass of the lumen bulk phase. In fact, findings that colon weight directly correlates with the faecal wet weight independently from the fermentability of the dietary fibre fed supports the notion that faecal bulk alone can represent a major factor determining colonic growth responses (Elsenhans et al. 1981; Whiteley et al. 1996). Despite the non-fermentable features of HEC, increases in microbial activities due to nutrients escaping into the large bowel cannot be excluded, however. This might add to changes specially in the caecum but also in the colon weight, particularly when a significant decrease in energy utilization indicates losses of nutrients as seen in rats fed the HV-HEC at a dietary concentration of $32 \%$.

The most obvious change of the small intestine after feeding carbohydrate gelling agents represents its elongation. This figure is somewhat problematic, however. Measuring the small intestine length certainly depends on the extent of stretching. To overcome this difficulty, measurements have been performed with the aid of defined weights attached to the small intestine, e.g. weights of 5 (Brown et al. 1979) or $10 \mathrm{~g}$ (Calvert et al. 1985) were used. Also measurements were carried out without a definite stretching just by putting the small intestine on a plane surface (Johnson et al. 1984), and there are other measurements without any detailed description. In this respect, the present method of using the weight of the small intestine on its own appears to be a kind of compromise.

Regardless of the kind of measurement, small-intestinal elongations of 10 to $20 \%$ were reported after feeding of carbohydrate gelling agents to rats at dietary concentrations of 5 to $20 \%$ (Brown et al. 1979; Farness \& Schneeman, 1982; Calvert et al. 1985; Johnson \& Gee, 1986). These findings and results of a previous study (Elsenhans $e t$ al. 1981) agree with data obtained in the present investigation. In this connection, it should be mentioned that in a fibre-free diet, additions of cellulose (Younoszai et al. 1978), but also of more complex dietary fibres such as oat bran (Farness \& Schneeman, 1982) did not lead to an elongation of the small intestine. This lack of an effect is also reflected by the present results of feeding a standard chow (STD diet).

Increases in the small intestine length by feeding HEC were accompanied by even larger increases in wet weight and mucosal mass. Accordingly, mucosal protein and, even more, DNA content were increased so that the results can be interpreted in terms of a hyperplasia of the small intestinal mucosa. The effect of the HEC in the ileum were slightly larger than in the jejunum which may indicate a higher responsiveness of the distal parts of the small intestine to trophic stimuli. It is well known that the rat small intestine develops an atrophy under the conditions of fibre-free feeding which can be 'normalized' by dietary additions of bulk (Ecknauer et al. 1981). The present results emphasize the effect of the viscosity on such a 'normalization'.

The mechanism for the increase in length and weight of the small intestine is certainly based on changes of the consistency of the lumen contents caused by the increased viscosity of the HEC fed. In relation to other observations about small intestinal elongations, an altered supply of nutrients from the lumen contents has to be considered as a mechanism, a process related to the so-called topical or luminal nutrition. That an impaired and, thus, delayed absorption of carbohydrates, i.e. a shift of digestive and absorptive processes from proximal into distal segments, can lead to increases in length and weight of the small intestine of rats was previously demonstrated by inhibition of starch digestion with $\alpha$-amylase inhibitors (Fölsch et al. 1981) and of disaccharide hydrolysis by $\alpha$-glucosidase inhibitors (Fölsch et al. 1978). Similarily, resistant starch with its slow glucose-releasing properties can produce such effects (Brunsgaard et al. 1995). The effect of such an induced delay in carbohydrate absorption on the weight increase of the small intestine, particularly in the distal half, was greater in fibre-free fed than in conventionally fed rats (Creutzfeldt et al. 1985).

The concept that changes in the luminal nutrition contribute to adaptive changes in the intestinal tract also includes interactions of the carbohydrate gelling agents with pancreatic, biliary and small intestinal secretions. Proteinpolysaccharide interactions are well-known so that adaptive changes may have been mediated by binding and inhibition of digestive enzymes which was demonstrated for various dietary fibres and carbohydrate gelling agents (Dunaif \& Schneeman, 1981; Isaksson et al. 1982). Binding and also inhibition of enzymes, however, depend on chemical interactions which might not be essentially altered when the molecular mass of the polysaccharide increases from 38000 to 185000 , as with the HEC employed in the present study. Therefore, potential binding and inhibitory effects of HEC, particularly at a given dietary concentration, may not have much contributed to the observed intestinal changes. Owing to the physico-chemical properties of HEC it is more likely that processes such as diffusion, mixing and sieving are influenced which certainly affects transport processes within the intestinal lumen. In this connection it is noteworthy that in previous work employing different carboxymethylcelluloses a vicosity-dependent reduction of pepsin activity was found in the stomach content (Larsen et al. 1994). Whether this was due to an altered secretion or an altered inactivation was not elucidated, however.

Adaptive changes of the small intestine by dietary fibre and related carbohydrate gelling agents are not only mediated by processes related to luminal nutrition. Mere physical actions, e.g. by distention, have to be considered as contributing factors (Gustafsson et al. 1970). Also the increased amount of physical work needed to propel the viscous content along the intestinal tract may provide a growth stimulus for 
the intestinal muscle layer (Brown et al. 1979). In fact, a previous study demonstrated hypertrophy of the tunica muscularis in the ileum and mid-colon of rats after pectin feeding (Stark et al. 1995).

Independent of the complex mechanisms involved in the adaptation of the morphology and function of the intestinal tract to various dietary regimens, the present results obtained with HEC clearly demonstrate that an increase in the viscosity of the ingested food, accomplished either by increasing dietary concentrations or employing derivatives of different molecular mass, can be one of the main factors in determining adaptive changes. To conclude this from findings with chemically-different polysaccharides at single dietary concentrations is more problematic since viscosities determined in vitro do not necessarily reflect the luminal viscosities which might result from application in vivo (Edwards et al. 1987; Cameron-Smith et al. 1994). When feeding additions of homologous polysaccharides with different molecular mass, however, one can assume a rather strong correlation between in vitro and in vivo viscosities.

\section{References}

Atkinson RL, Whipple JH, Atkinson SH \& Stewart CC (1982) Role of small bowel in regulating food intake in rats. American Journal of Physiology 242, R429-R433.

Braun WH, Ramsey JC \& Gehring PJ (1974) The lack of significant absorption of methylcellulose, viscosity $3300 \mathrm{cP}$, from the gastrointestinal tract following single and multiple oral doses to the rat. Food and Cosmetics Toxicology, 12, 373-376.

Brown RC, Kelleher J \& Losowsky MS (1979) The effect of pectin on the structure and function of rat small intestine. British Journal of Nutrition 42, 357-365.

Brunsgaard G, Eggum BO \& Sandström B (1995) Gastrointestinal growth in rats as influenced by indigestible polysaccharides and adaptation period. Comparative Biochemistry and Physiology 111A, 369-377.

Burton KA (1956) Study of the conditions and mechanism of the diphenylamine reaction for the colorimetric estimation of deoxyribonucleic acid. Biochemical Journal 62, 315-323.

Calvert R, Schneeman BO, Satchithanandam S, Cassidy MM \& Vahouny GV (1985) Dietary fiber and intestinal adaptation: effects on intestinal and pancreatic digestive enzyme activities. American Journal of Clinical Nutrition 41, 1249-1256.

Cameron-Smith D, Collier GR \& O'Dea K (1994) Effect of soluble dietary fibre on the viscosity of gastrointestinal contents and the acute glycaemic response in the rat. British Journal of Nutrition 71, 563-571.

Creutzfeldt W, Fölsch UR, Elsenhans B, Ballemann M \& Conlon JM (1985) Adaptation of the small intestine to induced maldigestion in rats. Experimental pancreatic atrophy and accarbose feeding. Scandinavian Journal of Gastroenterology 20, Suppl. $112,45-53$.

Croft DN \& Lubran M (1965) The estimation of deoxyribonucleic acid in the presence of sialic acid: application to analysis of human gastric washings. Biochemical Journal 95, 612-620.

Cummings JH (1982) Consequences of the metabolism of fiber in the human large intestine. In Dietary Fiber in Health and Disease, pp. 9-22 [VG Vahouny \& D Kritchevsky, editors]. New York, NY: Plenum Press.

Dowling RH, Riecken EO, Laws JW \& Booth CC (1967) The intestinal response to high bulk feeding in the rat. Clinical Science 32, 1-9.

Dunaif G \& Schneeman BO (1981) The effect of dietary fiber on human pancreatic enzyme activity in vitro. American Journal of Clinical Nutrition 34, 1034-1035.

Ecknauer R, Sircar B \& Johnson LR (1981) Effect of dietary bulk on small intestinal morphology and cell renewal in the rat. Gastroenterology 81, 781-786.

Edwards CA, Blackburn NA, Craigen L, Davison P, Tomlin J, Sugden K, Johnson IT \& Read NW (1987) Viscosity of food gums determined in vitro related to their hypoglycemic actions. American Journal of Clinical Nutrition 46, 72-77.

Elsenhans B, Blume R \& Caspary WF (1981) Long-term feeding of unavailable carbohydrate gelling agents. Influence of dietary concentration and microbiological degradation on adaptive responses in the rat. American Journal of Clinical Nutrition 34, 1837-1848.

Elsenhans B \& Caspary WF (1989) Differential changes in the urinary excretion of two orally administered polyethylene glycol markers (PEG 900 and PEG 4000) in rats after feeding various carbohydrate gelling agents. Journal of Nutrition 119, 380-387.

Epstein AN \& Teitelbaum P (1962) Regulation of food intake in the absence of taste, smell and other oropharyngeal sensations. Journal of Comparative Physiology and Psychology 55, 753759.

Farness PL \& Schneeman BO (1982) Effects of dietary cellulose, pectin and oat bran on the small intestine in the rat. Journal of Nutrition 112, 1315-1319.

Fischer JE (1957) Effects of feeding diets containing lactose, agar, cellulose, raw potato starch or arabinose on the dry weight of cleaned gastrointestinal tract organs in the rat. American Journal of Physiology 188, 550-554.

Fölsch UR, Grieb N, Caspary WF \& Creutzfeldt W (1981) Influence of short- and long-term feeding of an $\alpha$-amylase inhibitor (Bay e4609) on the exocrine pancreas of the rat. Digestion 21, 74-82.

Fölsch UR, Van Schwamen E, Graf S, Caspary WF \& Creutzfeldt W (1978) Einflu $\beta$ einer Langzeitfütterung eines Glykosidhydrolaseinhibitors auf die Pankreasenzymsekretion und Dünndarmbürstensaumenzyme der Ratte (Influence of long-term feeding of a glycoside-hydrolase inhibitor on pancreatic enzyme secretion and small-intestinal brush border enzymes in the rat). Ergebnisse in der Gastroenterologie 14, 78.

Gee JM, Lee-Finglas W, Wortley GW \& Johnson IT (1996) Fermentable carbohydrates elevate plasma enteroglucagon but high viscosity is also necessary to stimulate small bowel mucosal cell proliferation in rats. Journal of Nutrition 126, 373-379.

Gustafsson BE, Midvedt T \& Strandberg K (1970) Effects of microbial contamination on the cecum enlargement of germfree rats. Scandinavian Journal of Gastroenterology 5, 309-314.

Hiller HH \& Nebendahl K (1977) Möglichkeiten zur Einstellung des Energiegehaltes in Futtermischungen für Ratten unter besonderer Berücksichtigung von Hostalenpulver als Füllstoff (Adjustment of the energy content of food mixtures for rats with special regard to Hostalen powder as filler). Zeitschrift für Versuchstierkunde 19, 222-228.

Isaksson G, Lundquist I \& Ihse I (1982) Effect of dietary fiber on pancreatic enzyme activity in vitro. The importance of viscosity, $\mathrm{pH}$, ionic strength, adsorption and time of incubation. Gastroenterology 82, 918-924.

Johnson IT (1986) Effects of hydrophilic fiber sources in dry rat diets (letter to the editor). Journal of Nutrition 117, 403-404.

Johnson IT \& Gee JM (1986) Gastrointestinal adaptation in response to soluble non-available polysaccharides in the rat. British Journal of Nutrition 55, 497-505.

Johnson IT, Gee JM \& Mahoney RR (1984) Effect of dietary supplements of guar gum and cellulose on intestinal cell proliferation, enzyme levels and sugar transport in the rat. British Journal of Nutrition 52, 477-487.

Koopmans HS (1990) The role of the ileum in the control of food 
intake and intestinal adaptation. Canadian Journal of Physiology and Pharmacology 68, 650-655.

Koopmans HS \& Maggio CA (1978) The effects of specified chemical meals on food intake. American Journal of Clinical Nutrition 31, S267-S272.

Larsen FM, Wilson MN \& Moughan PJ (1994) Dietary fiber viscosity and amino acid digestibility, proteolytic digestive enzyme activity and digestive organ weights in growing rats. Journal of Nutrition 124, 833-841.

Lowry DH, Rosebrough NL, Farr A \& Randall RJ (1951) Protein measurement with the Folin phenol reagent. Journal of Biological Chemistry 193, 265-275.

Mallett AK, Wise A \& Rowland IR (1983) Effect of dietary cellulose on the metabolic activity of the rat ceacal microflora. Archives of Toxicology 52, 311-317.

Sachs L (1984) Angewandte Statistik (Applied Statistics), 6th ed. Berlin: Springer.

Schneeman BO (1994) Carbohydrates: significance for energy balance and gastrointestinal function. Journal of Nutrition 124, 1747S-1753S.
Southgate DAT (1978) Dietary fibre. Chemical aspects. Topics in Gastroenterology 6, 13-38.

Spiller RC (1994) Pharmacology of dietary fibre. Pharmacology and Therapeutics 62, 407-427.

Stark A, Nyska A, Zuckerman A \& Madar Z (1995) Changes in intestinal tunica muscularis following dietary fiber feeding in rats. A morphometric study using image analysis. Digestive Diseases and Sciences 40, 960-966.

Struthers BJ (1986a) Warning: feeding animals hydrophilic fiber sources in dry diets. Journal of Nutrition 116, 47-49.

Struthers BJ (1986b) Reply to the letter of Dr. Johnson. Journal of Nutrition 117, 405.

Whiteley LO, Higgins JM, Purdon MP, Ridder GM \& Bertram TA (1996) Evaluation in rats of the dose-response relationship among colonic mucosal growth, colonic fermentation, and dietary fiber. Digestive Diseases and Sciences 41, 14581467.

Younoszai MK, Adedoyin M \& Ranshaw J (1978) Dietary components and gastrointestinal growth in rats. Journal of Nutrition 108, 341-350. 